\title{
OS PROBLEMAS DO FUNDACIONISMO
}

\author{
Júlio César Burdzinski* \\ burdzinski@cfh.ufsc.br
}

RESUMO Este trabalho analisa o fundacionismo epistemológico, uma das principais alternativas de resposta ao problema do regresso epistêmico. Em particular, o autor pretende sistematizar aquelas que entende serem as dificuldades básicas que a proposta fundacionista deve superar para resolver satisfatoriamente o problema do regresso. Para tanto, acompanha as duas vertentes principais pelas quais circula o fundacionismo contemporâneo, a saber, a vertente internalista e a vertente externalista. Nesse acompanhamento, as noções de "justificação epistêmica" e de "crença básica" são prioritariamente avaliadas.

Palavras-Chave Justificação Epistêmica; Problema do Regresso; Fundacionismo; Crença Básica; Internalismo; Externalismo

ABSTRACT This work analyses the epistemological foundationism, one of the most important alternatives of answers to the problem of the epistemic return. In particular, the author intends to systematize those he believes to be the basic difficulties that the foundacionist proposal must overcome to solve, reasonably, the problem of return. Thus, he follows the two principal subjects through which the contemporary foundationism moves, namely, the internalistic truth and the externalistic truth. In this follow up, the notions of 'epistemic justification' and of 'basic belief' are preferably evaluated.

Keywords: Epistemic Justification; Problem of Return; Foundationism; Basic Belief; Internalism; Externalism

* Professor do Departamento de Filosofia da Universidade Federal de Santa Catarina. Artigo recebido em abril de 2006 e aprovado em março de 2007.

KRITERION, Belo Horizonte, nº 115, Jun/2007, p. 107-125. 


\section{Conhecimento, justificação e o problema do regresso}

Dentre os problemas centrais postos para a Teoria do Conhecimento contemporânea, destaca-se o da justificabilidade de crenças. Esse problema pode ser situado desde a assim chamada "definição tripartite" do termo "conhecimento proposicional". Essa definição, cujas origens podem ser creditadas ao Menon e ao Teeteto platônicos, propõe que o conhecimento seja identificado com a crença verdadeira justificada. De acordo com essa definição, portanto, uma análise do conhecimento nos apresenta o seguinte conjunto de condições necessárias e (supostamente) suficientes: ${ }^{1} 1$ ) a verdade da proposição que é conhecida; 2) a crença nessa proposição; 3 ) o fato de que o agente doxástico ${ }^{2}$ esteja justificado ao crer na proposição. ${ }^{3}$ A caracterização de cada uma dessas condições propõe-nos problemas específicos. Neste trabalho abordo algumas das questões ligadas à terceira das condições acima elencadas: a exigência de justificação epistêmica. Em particular, trato nas páginas que se seguem daquelas que me parecem ser as mais problemáticas implicações da mais tradicional das respostas ao problema do regresso epistêmico, a saber, $\mathrm{a}(\mathrm{s})$ teoria(s) fundacionista(s).

O problema do regresso epistêmico parece ter sido primeiramente formulado por Sexto Empírico e pode ser esquematicamente apresentado como segue. Que um sujeito $S$ qualquer esteja justificado em crer que $P$ (onde $P$ é uma proposição qualquer) depende da crença de $S$ numa segunda proposição $Q .{ }^{4}$ Se a caracterização da relação de justificação própria desse par doxástico deve poder ser em seguida generalizada, então a justificação da crença de que $Q$ deve depender da crença de que $R$, e assim por diante. De modo que, uma

1 De fato, o questionamento de que tais condições sejam suficientes para caracterizar o conhecimento constitui, por si só, uma poderosa fonte de polêmicas no campo da teoria do conhecimento, polêmicas que orbitam o chamado "problema de Gettier". A bibliografia acerca do tema é imensa; para um primeiro contato com o tema, talvez um bom ponto de partida seja o verbete "Gettier Problem" em (DANCY; SOSA, 1992).

2 A expressão "agente doxástico", que exaustivamente empregarei ao longo deste trabalho, é a tradução usual na comunidade epistemológica do termo "believer"; embora a tradução literal que imediatamente se apresente seja simplesmente o termo "crente", a conotação religiosa que a essa palavra imediatamente se associa na língua portuguesa sugere fortemente que esse é um dos casos em que a literalidade poderia prejudicar a compreensibilidade.

3 Essa condição pode ser entendida de maneira mais ampla como uma exigência de que a justificação esteja no campo de possibilidades do agente doxástico, uma vez que uma crença pode ser dita justificada não apenas quando o agente doxástico efetivamente expressa a justificação de que dispõe, mas, também, quando a possibilidade de que a crença possa ser justificada esteja assegurada.

4 Naturalmente, para que a crença de que $Q$ proporcione justificação epistêmica à crença de que $P$, deve existir entre ambas as crenças uma relação que preencha a série de condições necessárias e suficientes que caracterize esse tido de justificação. Existe na literatura epistemológica, como seria de se esperar, uma ampla polêmica acerca de quais seriam exatamente essas condições. Para a configuração esquemática do problema do regresso epistêmico aqui oferecida, entretanto, não será necessário ingressar nessa polêmica. 
vez que as estruturas de inferência tenham sido assumidas como paradigma da justificação epistêmica, apresenta-se, de forma cogente, o seguinte conjunto de alternativas: uma alternativa é prosseguir indefinidamente de inferência em inferência, mas essa alternativa, além de ser uma óbvia impossibilidade prática, é também uma posição teoricamente insustentável já que, por mais longa que seja a cadeia das razões e por mais fortes que sejam seus elos, ela não estará efetivamente ancorada em lugar algum; ${ }^{5}$ a recusa a prosseguir nessa infindável busca de razões pode conduzir à sustentação de um modelo circular da estrutura da justificação epistêmica, modelo logicamente viciado e, por isso mesmo, aparentemente condenado desde o princípio; ${ }^{6}$ a terceira alternativa é simplesmente suspender o regresso em algum ponto da cadeia. Essa alternativa, porém, pode assumir duas feições muito diferentes. Num primeiro caso, o regresso pode ser detido sem que qualquer justificativa para isso seja oferecida. ${ }^{7}$ Tal procedimento é epistemicamente insustentável, pois firma compromisso com a singular tese de que a justificação última é injustificada. Num segundo caso, no entanto, a seqüência é detida desde a suposição de que o elo último da cadeia é de natureza diversa daquela dos demais. A idéia é apresentar a justificação última como obedecendo a uma dinâmica diferente daquela da justificação inferencial - uma diferença que de algum modo evita que o problema seja reinstalado e o processo regressivo retomado. Essa última é a alternativa dita "fundacionista".

\section{O fundacionismo}

Seja do ponto de vista teórico, seja do ponto de vista histórico, dentre as teorias da justificação epistêmica, o fundacionismo tem prioridade. Essa posição privilegiada implica, como é natural em tais circunstâncias, um particular conjunto de vantagens e de ônus em relação às teorias competidoras. ${ }^{8}$

5 Naturalmente, defensores desta alternativa discordarão vigorosamente de tais afirmações. Uma referência obrigatória dessa posição epistemológica - dita "infinitista" - é Peter Klein (1999). Em um recente trabalho ainda inédito, Tito Flores (2004) assume a defesa do infinitismo.

6 Essa alternativa, conhecida como "coerentista" tem - ou teve - dois nomes destacados na literatura epistemológica contemporânea. Laurence BonJour (1985) articulou uma versão do coerentismo para o conhecimento empírico (versão a que, mais recentemente, o próprio autor renunciou). Keith Lehrer (2000) tem refinado uma versão bastante diferente ao longo dos últimos 30 anos.

7 Sem que seja oferecida qualquer justificativa epistêmica, entenda-se bem. Naturalmente, podem ser oferecidas razões de outro gênero - morais ou prudenciais, por exemplo.

8 O fundacionismo, não obstante a forma esquemática como o exporei aqui, não deve ser entendido como uma posição uniforme e monolítica. Uma forma (também esquemática, evidentemente, mas em menor grau) de compreendermos panoramicamente as muitas variações que ele pode assumir é enfeixá-las em duas classes: "fundacionismo forte" é como costumeiramente é chamado o conjunto de versões do fundacionismo que se caracteriza, como o indica o adjetivo, pela atribuição às crenças que estão na base 
De algum modo, estas precisam encontrar lugar para se afirmar disputando um espaço que antecipadamente está ocupado pelas idéias fundacionistas. ${ }^{9}$ Por isso mesmo, a mais tradicional forma de apresentação das teorias da justificação epistêmica se dá a partir da análise do fundacionismo e, eventualmente, da subseqüente denúncia dos defeitos fundamentais que terminam por minar a sua inicial credibilidade. É exatamente esse o caminho que seguirei aqui. E esse caminho será percorrido em dois momentos: no primeiro, considerarei a clássica abordagem internalista; no segundo, me deterei sobre a relativamente recente e inovadora perspectiva externalista.

Antes de prosseguir, porém, devo observar que não alimento em absoluto a pretensão de que os problemas que a seguir apresento sejam inéditos na literatura epistemológica contemporânea. Ao invés, apresento-os aqui porque creio que eles representam uma seleção relevante de críticas repetidamente articuladas desde diversos pontos de vista, motivadas por circunstâncias muito diversas e inseridas em contextos muito diversos. Por isso mesmo, o que, sim, pretendo é oferecer uma formulação sistemática e em algum grau esclarecedora daqueles que penso serem os problemas fundamentais para os quais o fundacionismo epistemológico deve apresentar respostas. Que, não obstante, todo o esforço e talento empregue por fundacionistas de todas as épocas e matizes, tais respostas ainda não tenham se revelado de todo satisfatórias, é situação que pode ser alvo de mais de uma leitura. Fundacionistas alegarão talvez que isso nos diga algo sobre a magnitude e complexidade da tarefa proposta. Seus adversários, porém, poderiam argumentar que deveríamos investir mais vigorosamente nas propostas alternativas. Este trabalho não assume compromisso com quaisquer de tais leituras, já que o objetivo aqui é exclusivamente o de caracterizar as dificuldades produzidas pela assunção daqueles supostos teóricos fundacionistas que parecem ser indispensáveis até mesmo para a caracterização apropriada de tais teorias.

da cadeia de justificação da capacidade de justificarem completa e autonomamente todas as crenças que dela dependem ao longo dessa cadeia; "fundacionismo fraco", por oposição, é o título que identifica as variantes do fundacionismo que reconhecem nas crenças básicas apenas uma capacidade limitada de justificação e que, por isso mesmo, precisa ser complementada por outras fontes como, por exemplo, a própria relação de coerência entre as crenças.

9 Eis porque, da mesma forma como os desafiantes de um torneio de boxe só podem almejar a conquista do título máximo de sua categoria pelo enfrentamento direto ou pela renúncia do campeão já estabelecido, uma teoria da justificação epistêmica de vertente coerentista - e a esse respeito o mesmo é inteiramente válido, parece-nos, para qualquer teoria que não se adapte ao figurino fundacionista - precisa, senão derrotar, ao menos manter o fundacionismo sob estrita vigilância e exercer sobre ele permanente controle. Que essa tarefa não é simples nem sempre exitosa o comprova o recente nocaute de que foi vítima Laurence BonJour, até há pouco um dos campeões do coerentismo. A esse propósito, ver BonJour (1999). 


\section{O fundacionismo internalista}

Em um artigo publicado originalmente em 1978, Laurence BonJour assim caracteriza o núcleo invariável de diferentes teorias fundacionistas:

(...) a tese central do fundacionismo epistemológico, tal como eu o entenderei aqui, é a alegação de que certas crenças empíricas possuem um grau de justificação ou de garantia epistêmica que não depende, inferencialmente ou de outra maneira, da justificação de outras crenças empíricas, mas são, ao invés, de alguma maneira, imediatas ou intrínsecas. ${ }^{10}$

Na raiz dessa tese, encontra-se o argumento do regresso epistêmico. É ele que inicialmente dá forma ao problema para o qual o fundacionismo pretende ser a melhor ou mesmo a única resposta. E, de fato, é difícil evitar a idéia de que deve haver, na base mesma da cadeia da justificação, uma crença de tipo especial, uma crença que proporciona a justificação de que as crenças subseqüentes necessitam e que, ao mesmo tempo, não necessita buscar seu fundamento em qualquer outra crença, haurindo assim sua justificação de alguma outra fonte. Quaisquer alternativas dão a clara impressão de nos comprometer com algum tipo de irracionalidade e nos conduzir, por fim, ao ceticismo. Assim, no ceticismo parecem redundar, não apenas a negação pura e simples da justificação mas, igualmente, tanto a alternativa infinitista (uma justificação que exige um regresso infinito parece propor exigências que não se podem satisfazer), quanto o coerentismo (permanentemente ameaçado pela mortal acusação de que nele assumimos algum tipo de circularidade viciosa). Nesse cenário, o fundacionismo - e em particular o fundacionismo internalista - galante, porém firmemente, impõe-se como a resposta mais simples e mais óbvia ao problema do regresso epistêmico. Para recusarmos tal imposição devemos olhar mais atentamente e desvelar os problemas que se escondem

10 BONJOUR, 1978, p.95. (A tradução desta e das demais passagens citadas é de responsabilidade do autor deste trabalho). Em BonJour (1985, p. 16-17) a caracterização do fundacionismo assume uma feição mais desenvolvida: "a posição fundacionista toma várias formas, e algumas das diferenças se revelam filosoficamente cruciais. Mas o denominador comum entre elas, a tese central do fundacionismo epistemológico tal como este é entendido aqui, é a tese dupla: (a) de que algumas crenças empíricas possuem uma medida de justificação epistêmica que é de alguma maneira imediata ou intrínseca a elas, ao menos no sentido de não serem dependentes, inferencialmente ou de outra maneira, da justificação epistêmica de outras crenças; e (b) de que são essas 'crenças básicas', como elas são às vezes chamadas, que são a fonte última de justificação para todo o conhecimento empírico. Todas as outras crenças empíricas, nesta perspectiva, derivam qualquer justificação que elas possuam de suas apropriadas relações inferenciais ou evidenciais com os membros dessa classe epistemicamente privilegiada. $E$ em virtude desse papel epistêmico central, esses moventes imóveis (ou, talvez, automovidos) do reino epistêmico, como Chisholm apropriadamente os chamou, constituem a fundação sobre a qual repousa o conhecimento empírico". 
por detrás das ilusórias simplicidade e obviedade da solução fundacionista. $\mathrm{Na}$ seqüência, destacarei dois desses problemas.

\section{Primeiro problema}

Se uma crença deve servir de suporte para outra, ela própria deve, de início, dispor de sustentação. Em particular, se esse suporte deve ser do gênero da justificação epistêmica, ele deve ser capaz de ter a indispensável conexão com a (probabilidade da) verdade que tal tipo de justificação não pode dispensar sob pena de tornar-se epistemicamente irrelevante. É um lugar-comum afirmar que crenças podem justificar e podem ser justificadas. Mas o que em uma crença, exatamente, oferece ou requer justificação? A forma ao mesmo tempo mais clara e mais direta de dar uma resposta a essa questão pode partir de uma definição elementar de crença. Tomemos uma: crenças "são um estado psicológico disposicional em virtude do qual uma pessoa irá assentir a uma proposição sob certas condições". ${ }^{11}$ Ora, se a crença é uma disposição para dar nosso assentimento a uma proposição, então é a proposição - alternativamente, o conteúdo assertivo da crença -, à qual tal assentimento será dado, que guarda a chave para a resposta à questão que nos ocupa. E uma vez que é na justificação de crenças que estamos interessados, teremos de considerar a relação entre um par de crenças onde uma delas exerce o papel de justificadora e a outra o de justificada. Nesse caso em particular encontraremos uma situação na qual a disposição para dar assentimento a uma dada proposição, digamos, $p$, vincula-se justificatoriamente (por hipótese) com a disposição para dar assentimento a uma outra dada proposição, digamos, $q-\mathrm{e}$ isso de um modo tal que a manutenção da disposição para assentir a $p$ dá sustentação para a manutenção da mesma disposição também em relação a $q$. Esse tipo de vínculo, a que chamamos justamente de justificação, é estabelecido desde o conteúdo assertivo da crença. Desse modo, se uma crença dará (ou receberá) sustentação de uma outra crença é algo a ser decidido desde a consideração do conteúdo assertivo de cada uma delas. É ele que nos permitirá decidir, seja pela caracterização da crença como justificada, seja pela sua caracterização como justificadora. É um e o mesmo o fator presente na crença, portanto, aquele que concede e aquele que recebe a justificação.

11 A definição que tomo aqui por exemplar é a de Paul K. Moser, do verbete "belief" do The Cambridge Dictionary of Philosophy (In: AUDI, 1999). A caracterização do conceito de crença é palco de amplos e profundos desacordos, desacordos esses nos quais não pretendo adentrar. O conceito de Moser que tomo como referência deve, por isso mesmo, ser tomado aqui unicamente nas implicações que ele traz para a relação entre crenças e proposições, implicações essas que serão desenvolvidas na seqüência do texto. 
Se essa descrição da justificação de crenças está correta, podemos concluir que, quando afirmo que a crença de que $q$ está justificada, estou afirmando, abreviadamente, que é o assentimento que dou a $p$ o que sustenta a minha disposição para dar assentimento a $q$. A articulação doxástica se articula assim sobre os respectivos conteúdos assertivos. Creio justificadamente que $q$ muito simplesmente porque creio que $p$. Por óbvio, a crença de que $p$, ela própria, precisa estar justificada e, se desafiado, devo poder exibir a justificação que tenho para ela, apresentando, nessa ocasião, digamos, minha crença de que $r$. Vemos assomar-se dessa maneira o problema do regresso. Mas, adicionalmente, na caracterização que agora produzi, vemos destacar-se um aspecto em particular do regresso que, quiçá, não tenha antes se apresentado com a necessária clareza. Ocorre que, se a justificação se articula doxasticamente a partir dos conteúdos assertivos, então a idéia mesma de crenças básicas começará a parecer agora uma idéia particularmente singular; em todo o caso, já não parecerá uma idéia tão óbvia e simples quanto o fundacionista inicialmente nos terá feito crer.

Em termos metafóricos, o que o fundacionista nos pede para conceber é algo como o elo primeiro de uma corrente, um elo que fixa esta em uma superfície sólida e que faz com que ela cumpra a função de ligar e dar sustentação para a qual presumivelmente foi projetada. Tal elo não é nem pode ser da mesma natureza dos demais. Elos ordinários, com efeito, ligam-se uns aos outros (têm, de um lado e de outro, algo da mesma natureza que eles próprios); o elo primeiro que buscamos, porém, deve fundir-se àquilo que lhe dá sustentação. De um lado, é um elo da cadeia; de outro, não é mais elo, mas sim alguma coisa diferente, é base, fundação, alicerce. Ele é um primeiro elo que já não seja inteiramente elo, é uma criatura de dois mundos.

Que essa imagem seja imprópria para compreender a cadeia da justificação deveria já ser sugerido pela circunstância de que a amarração física dos elos de uma corrente tem um caráter eminentemente exterior. Crenças, porém, são criaturas de natureza subjetiva. Mais claramente: em termos de justificação de crenças, não basta que essas crenças estejam fixadas, ${ }^{12}$ é indispensável que essa fixação seja percebida enquanto tal pelo agente doxástico. $\mathrm{O}$ que não se consegue ver nessa versão do fundacionismo, é como evitar que essa percepção tenha ela própria de ser justificada, seja por meio de uma referência ao gênero de percepção em jogo (dando conta de que ela seja conducente à verdade) ou a alguma coisa equivalente. De todo modo, se a necessidade de tal

12 Assumir a suficiência disso conduziria à posição externalista, uma singular variante do fundacionismo cuja incapacidade de oferecer uma resposta relevante ao problema do regresso tentarei na seqüência destacar. 
justificação for admitida - como parece inevitável - o problema do regresso terá sido reinstalado.

Para que a sugestão fundacionista cardinal - a saber, a sugestão de que encontremos algo distinto das crenças comuns para funcionar como fundamento desde o qual se articula toda justificação - possa ser levada adiante, precisamos encontrar alguma coisa cuja natureza seja conferir justificação sem dela carecer - ou, ao menos, sem dela carecer da maneira acima descrita. Sem, portanto, ostentar justificação à moda inferencial. Onde, porém, encontrar tal criatura? E o que pode ser essa criatura híbrida e com o que ela se pareceria se viesse a existir? ${ }^{13}$ No caso das crenças ordinárias, é em seu conteúdo assertivo - nas proposições que residem no coração das crenças - que se ancora afinal todo o processo de justificação. Mas ali a justificação é tanto dispensada quanto demandada. No caso das supostas crenças básicas, no entanto, não é possível que a justificação seja por elas demandada na forma de uma nova crença: nesse caso a própria basicidade estaria em xeque.

Como quer que essa questão seja em seguida encaminhada, uma coisa é certa: tais crenças precisam dispor de algum tipo de justificação. O problema aqui é compreender de que tipo de justificação um fundacionista pode dotar as crenças que ele supõe serem básicas. Como foi exposto mais acima, a crença de que $p$ pode justificar a crença (não-básica) de que $q$ em função dos conteúdos assertivos de cada uma delas. Se agora supusermos que a própria crença de que $p$ é uma crença básica, como entenderemos a circunstância de que seu conteúdo assertivo dispensa o mesmo tipo de justificação que ela própria proporciona a $q$ ? Concedido que a crença de que $p$ não pode dispensar algum tipo de justificação, deveremos sustentar que ela está, digamos, autojustificada (ou é auto-evidente, ou o que for). Parece óbvio, entretanto, que não poderemos estar a afirmar com isso simplesmente que a crença de que $p$ justifica a crença de que $p$ ao modo inferencial. Tampouco parece ser uma boa saída dizer que uma experiência qualquer justifica essa nossa crença em particular. A única experiência que poderia justificar nossa crença de que $p$ seria a nossa experiência específica de que $p$ (i.e., uma experiência que tivesse

13 Pois, afinal, qual seria sua natureza se ela não puder ser caracterizada ao modo assertivo com que descrevemos as crenças? Seria ela uma crença "semi-assertiva"? A própria noção de "semi-assertividade", porém, parece quimérica.

BonJour (1978) associa a busca desse ente híbrido com a tradicional teoria metafísico-epistêmica do dado, teoria que justamente assume a existência de uma certa dimensão da realidade que (supostamente) se apresenta sem mediações epistêmicas - lingüísticas ou de qualquer outra natureza - diante do sujeito. Trata-se assim de algo que nos é imediatamente familiar ou diretamente percebido ou instantaneamente apreendido - numa palavra, daquilo que é dado - ao invés de transcendental, conceitual ou lingüisticamente elaborado. 
esse específico conteúdo assertivo), mas essa experiência mesma não parece conter nada além - ao menos no que importa para a sua justificação - do que a própria experiência doxástica de crer que $p$. Está aberta também, claro, a possibilidade de que uma tal experiência seja acompanhada pela crença de que $r$ e de que seja afinal essa última experiência que justifique a crença de que $q$. Isso seria algo muito razoável; claro, uma tal conclusão implicaria que a crença de que $q$ não tem o status inicialmente suposto. Em suma: a crença básica de que $p$ exige justificação e, se essa justificação deve ser produzida doxasticamente, então, ou temos aí um raciocínio de tipo circular, ${ }^{14}$ ou devemos recusar a ela a condição de legítima base epistêmica.

A alternativa imediata pareceria ser, então, considerarmos que crenças básicas não são justificadas por outras crenças, liberando assim a basicidade de seu aspecto doxástico. Com esse aspecto, porém, parece ser perdida igualmente a assertividade que, vimos de ver, está a ela intimamente associada e, sem esta, não se vê como a justificação poderia de qualquer modo continuar desempenhando adequadamente o papel epistêmico que lhe cabe. E, enfim, se a justificação já não exerce devidamente tal papel, a proposta fundacionista inteira parece fracassar. Essa opção conduzir a tal fracasso epistêmico não deveria nos surpreender, entretanto: que na base de uma cadeia de crenças justificadas cogitemos de encontrar um fator não-doxástico é por si só uma suposição tão singular que, o que quer que daí decorra, já não deveria mais causar qualquer espanto.

A idéia mesma de "crenças básicas" parece desse modo condenada: se algo é uma crença, não pode ser alguma coisa básica - terá um caráter assertivo que necessariamente se projeta em ambos os sentidos de uma relação de justificação; se algo é básico, não pode ser alguma coisa doxástica - qualquer fundamentação que possa oferecer terá um caráter externo, sendo assim inacessível a qualquer avaliação subjetiva. A justificação epistêmica, no entanto, deveria ser entendida como uma ponte entre subjetividade e objetividade, entre nossas crenças e a verdade das proposições que estas alvejam, pelo que nenhuma caracterização desse tipo de justificação que dispense sua acessibilidade desde um ponto de vista subjetivo parecerá satisfatória. ${ }^{15}$

14 Circularidade esta que é, curiosamente, a crítica favorita que fundacionistas costumam dirigir a coerentistas.

$15 \mathrm{O}$ argumento anti-fundacionista que apresentei nesta seção é amplamente inspirado em BonJour (1985), particularmente em seus capítulos 2 e 4 . Variações do mesmo argumento tal como desenvolvido pelo próprio BonJour podem ser encontrados em BonJour e Sosa (2003, p. 5-23). Embora eu tenha tentado conservar aqui o espírito da argumentação do autor, não tive a pretensão de apresentar aqui um mero 


\section{Segundo problema}

Como já foi destacado, o fundacionismo não se apresenta como uma posição monolítica no cenário das teorias da justificação epistêmica. Muitas são as variantes que ele admite e desde muitos pontos de vista podem essas ser agrupadas. Um critério que parece particularmente valioso para a distinção entre tipos diversos de fundacionismo é o que separa as várias formas de fundacionismo com base na distinta avaliação que eles fazem da natureza das supostas crenças básicas. Que esse ponto seja fundamental para a compreensão e avaliação crítica da proposta fundacionista já terá ficado claro. Suspendamos por ora o ceticismo a respeito da possibilidade mesma da existência de coisas como crenças básicas - ceticismo que, espero, a seção anterior terá fomentado no leitor - e concedamos que, a despeito da estranheza que essa idéia provoca (me provoca, em todo o caso), elas de fato se constituam em terminal e arrimo de cadeias de justificação epistêmica. Concedido isso, perguntemos: que tipo de suporte elas proporcionam? Duas respostas parecem disponíveis. A primeira é afirmarmos que esse estrato doxástico basilar é absolutamente firme e que não cabem meios-termos a propósito de tais crenças básicas. A segunda resposta em princípio disponível é conceder que a base concedida por tais crenças não precisa ser necessariamente um leito rochoso doxástico mas que, ao invés, ele admite graus e varia em consistência e firmeza. Assumida essa distinção, teremos um critério para separar as teorias fundacionistas falibilistas das teorias fundacionistas infalibilistas.

Se o fundacionismo é, dentre as teorias da justificação epistêmica, aquela que tem histórica e teórica precedência, o infalibilismo, com naturalidade, adquire proeminência dentre suas variantes. $\mathrm{O}$ fundacionismo infalibilista é a versão do fundacionismo que parte da idéia de que na base da cadeia da justificação encontramos crenças que se caracterizam pela sua infalibilidade. ${ }^{16}$ O infalibilismo surge como um candidato nato ao posto de fundacionismo-mor porque ele permite estabelecer uma ligação sem emendas entre justificação e verdade. Existem pelo menos dois grupos de crenças que tradicionalmente têm sido apresentadas como infalíveis: o conjunto das crenças em proposições analíticas e o das crenças introspectivas. A infalibilidade do primeiro

arremedo daquela argumentação. Ao invés, motivado pelo que considero ser a intuição correta ali presente, tentei destacar o que parece ser o problema central da posição fundacionista tal como vista desde minha própria perspectiva.

16 Uma crença é dita ser infalível na medida em que ela é uma crença em uma proposição cuja verdade é inquestionável, enquanto que uma crença é dita ser irresistível se ela impõe forçosamente que creiamos na verdade da proposição que ela tem por alvo. Crenças incorrigíveis serão aquelas que preenchem ambas as condições - a esse propósito, ver Lehrer (2000, p. 53). 
conjunto decorre da circunstância de que, em tais proposições, a verdade é uma consequiência direta da relação entre os conceitos empregados na formulação da proposição. No segundo caso, a infalibilidade parece repousar na circunstância de que, diferentemente daquilo que pensamos acerca de como de fato é o mundo, não parece que possamos estar enganados no que diz respeito ao que pensamos acerca de como ele nos aparece. Tais casos nos dão razões suficientes para aceitarmos o infalibilismo? Keith Lehrer sugere que não:

A falibilidade infecta quase todas as nossas crenças. Mais importante, entretanto, é o fato de que a infalibilidade de crenças infalíveis pode ser opaca ao sujeito de modo que o sujeito não tenha idéia de que as crenças são infalíveis. A infalibilidade é uma característica de uma crença que é ela própria não-básica, isto é, a crença de que a crença é infalível precisa ser justificada pelo argumento ou, ao menos, pela evidência. ${ }^{17}$

Crenças à primeira vista infalíveis podem acabar por revelarem-se carentes dessa propriedade. ${ }^{18}$ Uma vez que não encontramos no campo epistêmico um conjunto minimamente significante de crenças infalíveis, a justificação do grande número de crenças que ordinariamente consideramos justificadas pode resultar problemática. Mais fundamental ainda, há o problema do acesso. Ocorre que não é suficiente que uma crença seja infalível; é preciso que essa infalibilidade seja reconhecida enquanto tal pelo agente doxástico. Na ausência desse reconhecimento, a infalibilidade não produzirá nenhum benefício em termos de justificação.

Para ver que isto é assim, basta considerar o caso em que um sujeito tenha uma crença infalível qualquer - digamos, uma crença em uma proposição analítica - sem reconhecer essa infalibilidade (nesse caso, sem identificar a analiticidade da proposição). Numa tal circunstância, é perfeitamente possível conceber que esse sujeito sustente sua crença desde uma outra crença injustificada qualquer (ele pode, por exemplo, equivocadamente considerar que foi empiricamente provado que a proposição na qual crê é verdadeira). O que esse caso parece mostrar é que a infalibilidade de uma crença não produzirá o efeito justificatório desejado senão sob a condição de que tal crença seja sustentada justamente porque é infalível. Isso, por sua vez, exige

17 LEHRER, 2000, p. 67-68.

18 Lehrer (2000, p. 54-58) examina alguns de tais casos. Na revelação daquela carência a especificidade do conceito de aceitação diante do conceito mais tradicional de crença desempenha não pequena função. Ocorre que, para Lehrer, a aceitação implica um caráter funcional, de modo que não basta que eu professe uma certa crença, é preciso também que eu aja de acordo com ela para que possa ser dito aceitá-la. 
que esse caráter de infalibilidade seja de alguma maneira identificado. Essa identificação, finalmente, dependerá de algum tipo de avaliação da crença em questão, avaliação que não poderia partir senão das outras crenças que o sujeito sustenta e de uma consideração a respeito da especificidade de certas crenças - aquelas infalíveis - em confronto com as demais crenças que compõem o seu sistema doxástico. E, claramente, uma avaliação desse tipo não é, ela própria, infalível. Ao contrário, ela parece depender de uma consideração caso a caso de nossas crenças frente aos padrões epistêmicos que sustentamos.

O mesmo ponto pode ser destacado desde uma perspectiva talvez mais esclarecedora, afirmando que a infalibilidade das crenças que possam eventualmente compor meu sistema doxástico é insuficiente para proporcionar justificação para essas crenças. Ocorre que a justificação de crenças passa, senão pela exibição das razões de que disponho para sustentá-las, ao menos pela presença de tais razões em meu sistema doxástico. Se for assim, parece inútil, do ponto de vista da justificação, apontar para uma qualidade específica de algumas de minhas crenças, se essa qualidade não exerce papel decisivo na sustentação epistêmica delas. E, evidentemente, dado que o sujeito doxástico não identifique a presença da qualidade nas crenças em jogo, ela não poderia exercer qualquer papel naquela sustentação, muito menos um de caráter decisivo.

Resta assim o fundacionismo falibilista. Este, porém, na medida em que carece do sólido fundamento que o infalibilismo pretende reconhecer nas crenças básicas, abre mão da garantia de uma transição imediata da justificação para a verdade, abandonando assim aquela que é uma das mais atrativas características do fundacionismo. Entra em jogo então a consideração da crença supostamente básica em relação às demais crenças e também a avaliação dessa crença desde o ponto de vista da probabilidade de sua correção. Com isso, o fundacionismo falibilista diminui significativamente a distância que separa as supostas crenças básicas das crenças não-básicas e, dessa maneira, prepara o caminho para uma avaliação comum de todas elas. Naturalmente, deixa de fazer sentido considerar básicas as crenças que precisam ser assim avaliadas. Ao invés, a justificação de cada crença em particular deverá ser então obtida a partir de um tipo de articulação entre essa crença e o conjunto doxástico do qual ela faz parte.

Se as alegadas crenças básicas não garantem sua verdade, então a justificação para aceitar aquelas crenças na busca pela verdade precisa depender de outras informações ou crenças. As alegadas crenças básicas irão fracassar em ser autojustificadas. Toda aceitação justificada de crenças, mesmo do pequeno número de crenças infalíveis, irá depender de alguma informação de base que nós possuamos sobre a nossa 
competência para determinar se os conteúdos das crenças são verdadeiros ou falsos. Nosso conhecimento depende dessa informação de base. ${ }^{19}$

Para sumariar: quando, por suposição, chegamos às crenças básicas, ou estas se apresentam infalíveis ou não. No caso de nos restringirmos às crenças infalíveis - e uma vez que tenhamos inicialmente nos assegurado de que haja um número suficiente de tais crenças a fim de que o substrato doxástico seja, além de suficientemente sólido, suficientemente amplo para sustentar as crenças que ordinariamente consideramos justificadas - devemos nos assegurar também de que o sujeito doxástico tenha acesso à infalibilidade das crenças básicas a fim de que algum benefício resulte para a justificação das demais crenças. Caso as crenças básicas sejam consideradas falíveis, a justificação que tais crenças podem proporcionar terá de ser avaliada em função de sua probabilidade.

Mais uma vez, o problema do regresso epistêmico assoma no horizonte; e, com ele de novo à vista, o fundacionismo parece estar em sérias dificuldades justamente naquele ponto que constitui, senão sua maior força, ao menos sua motivação primeira: o apelo intuitivo da idéia de um fundamento epistêmico. $\mathrm{Na}$ tentativa de resgatar tal apelo, em período recente veio à luz uma nova proposta epistemológica. Essa proposta, conhecida como "externalista", compartilha com o fundacionismo clássico a noção de que a estrutura da justificação epistêmica se articula a partir de uma base que, embora justificada, está justificada de maneira não inferencial. Ao contrário do fundacionismo clássico, porém, o externalismo não exige que o sujeito doxástico tenha acesso subjetivo a essa base. Devo agora, portanto, submeter à análise esse tipo diferente e relativamente novo de fundacionismo, um fundacionismo que parte do suposto de que o sujeito doxástico não necessita ter acesso à justificação de sua crença a fim de nela estar justificado. Quais são as consequiências de tal suposição?

\section{O fundacionismo externalista}

Ao dispensar o sujeito doxástico do reconhecimento da crença justificatória enquanto tal, o fundacionista externalista toma um caminho particularmente heterodoxo. Não se trata, nesse caso, de efetuar apenas um reparo na sua concepção original, mas de conduzir uma ampla rearticulação da maneira como o próprio problema da justificação deve ser equacionado. Basta considerar a 
esse propósito que, ao eximir o sujeito da justificação da responsabilidade de contar com uma crença justificadora em seu sistema doxástico, o que se está a promover é a um banimento da questão da justificação - e, por extensão, também daquela do conhecimento - da subjetividade; ela torna-se, a rigor, um problema externo a esse sujeito. Daí justamente porque uma teoria assim caracterizada é denominada de "externalista". Daí, também, porque semelhante opção isenta o sujeito doxástico de qualquer responsabilidade de natureza epistêmica. Como responsabilizar alguém por crer ou deixar de crer numa proposição qualquer se a justificação - ou a falta dela -, não apenas the pode ser inacessível, mas é francamente assumida como algo que nada tem a ver com a sua subjetividade?

Desse ponto de vista externalista, examinar a justificação de uma determinada crença é examinar as condições causais determinantes da crença nessa específica proposição. Se tais condições implicam (na maior parte das vezes) a verdade dessa proposição, então a crença nela está justificada. Caso contrário, ela carece de justificação. O ponto fundamental aqui é que em momento nenhum o sujeito doxástico necessita estar justificado em crer, seja em que as condições em questão implicam a verdade da proposição, seja em que ele está correntemente submetido a tais condições. A justificação depende única e exclusivamente da configuração atual do mundo, do estado de coisas, como se costuma dizer, que determina a (provável) verdade da proposição em que crê o sujeito e que está por isso mesmo justificado. Essa singular caracterização dos problemas da justificação e do conhecimento conheceu alguma notoriedade em décadas recentes, sendo que seu mais notório paladino seja, talvez, Alvin Goldman. ${ }^{20}$ Quaisquer que sejam os méritos da epistemologia de vertente externalista no que diz respeito a outros aspectos da compreensão dos processos cognitivos, quando se chega à teoria da justificação epistêmica ela não pode deixar de soar - estridentemente, aos ouvidos educados na tradição cartesiana -, como particularmente exótica.

O externalismo, como de resto ocorre com quaisquer outras vertentes da teoria do conhecimento, não constitui uma posição monolítica. Muitas são as variantes que merecem ou reivindicam esse título e encontrar um traço em comum entre elas - algo que justifique inclusive a sua inclusão nesse mesmo título - não parece ser tarefa fácil. Numa caracterização de Keith Lehrer, tal comunidade é encontrada no apelo ao caráter naturalístico que elas revelam.

20 O artigo de Goldman, "What is Justified Belief” (1979), é uma referência clássica. Dretske (2000) reúne um belo conjunto de textos desse outro nome importante do externalismo. 
A análise tradicional diz que o conhecimento é crença verdadeira junto com o tipo certo de justificação. Um tipo de análise externalista diz que o conhecimento é crença verdadeira junto com o tipo certo de relação naturalística. É plausível supor que o relacionamento naturalístico será um que concerne a como a crença surge, em resumo, à história natural da crença. ${ }^{21}$

A plausibilidade de uma concepção naturalística do conhecimento parece depender de forma fundamental de uma intuitivamente correta descrição da obtenção de crenças sobre dados empíricos, a partir de experiências perceptivas que essa concepção proporciona. Não obstante, tal descrição traz consigo o que poderíamos considerar um fatal defeito de nascença, qual seja, a ausência de uma consideração de tais crenças do ponto de vista do próprio sujeito que as mantém. Em particular, casos em que alguém detém informação mas não é capaz de se pronunciar acerca da confiabilidade de tais informações - casos típicos nas ilustrações externalistas do conhecimento - indicam que, nessa concepção, o elemento justificatório que, segundo qualquer descrição internalista, é componente indispensável para o conhecimento, parece, ou completamente ausente, ou descaracterizado a tal ponto que já não pode ser reconhecido. Nessa situação, o suposto sujeito do conhecimento já não pode considerar sua crença desde o ponto de vista de sua verdade ou falsidade. Ora, sob qualquer consideração intuitivamente plausível do conhecimento, essa é uma marca característica das situações nas quais não reconheceremos sua posse por parte do sujeito.

Poderemos, é claro, admitir que, em tais circunstâncias, ele é um portador de informações. Tais informações poderão, dado que tal sujeito tenha acesso a elas e as avalie segundo os critérios da justificação epistêmica, ser elevadas ao status de conhecimento; não, porém, antes, nem muito menos independentemente, disso. Em circunstâncias de intransparência, no entanto, a flecha da justificação já não encontra o alvo da verdade. De fato, já não é o jogo do conhecimento que estamos jogando, então. Converter, ao modo externalista típico, o conhecimento numa questão de confiabilidade das condições de formações de nossas crenças implica em reduzi-lo a um problema relativo apenas à obtenção não-acidental de verdades. $O$ conhecimento - ou, se preferirem, o conhecimento em sua manifestação mais completa, a

21 LEHRER, 2000, p. 179. Como é sabido, a caracterização mesma do que é uma teoria naturalística é fonte de muitas polêmicas. Fiquemos, portanto, também aqui com a caracterização de Lehrer de uma tal teoria: "O que é uma teoria naturalística? É uma teoria na qual todos os termos usados na análise são tais que descrevem fenômenos da natureza, tais como causação, por exemplo, ou que podem ser reduzidos a tais termos. A teoria da crença de Hume foi naturalística neste sentido. Ele restringiu sua descrição do conhecimento humano a relação de causação, de contigüidade e de semelhança" (LEHRER, 2000, p. 178). 
saber, aquela tipicamente presente em seres humanos adultos que têm suas capacidades cognitivas intactas ${ }^{22}$ - é mais do que isso. Os meios confiáveis de obtenção de verdades precisam revelar sua confiabilidade e, por isso, não basta que uma crença tenha sido obtida de forma confiável: ela precisa também parecer tê-lo sido ao próprio agente.

Tal desconexão entre os fatores externos determinantes do conhecimento e os fatores internos - o acesso e talvez mesmo a possibilidade da avaliação do status justificatório das crenças - parece assim condenar o externalismo (ao menos o externalismo em sua roupagem tradicional) à descrição e à análise de situações pré-epistêmicas. Como quer que seja apreciado o mérito dessa abordagem, é inegável que o externalismo não responde ao problema do regresso. Não lhe responde, claro, porque sequer o coloca. E, entretanto, é justamente tal problema que tem estado sempre em nosso horizonte e que de um modo ou de outro parece orientar e servir de cenário às teorias da justificação epistêmica mais tradicionais. Para ocupar um lugar nesse cenário, o externalismo deveria oferecer um esclarecimento da conexão (ou da ausência desta) entre racionalidade e justificação. É a ausência de tal esclarecimento que parece manter essa posição epistemológica - sob diversos outros aspectos respeitável - aquém daquilo que seria necessário. Nas palavras de BonJour,

o externalista precisa, ou explicar como a satisfação de uma condição meramente externa pode tornar racional, para eu aceitar, uma crença com o objetivo de alcançar a verdade, mesmo admitindo que eu não tenha razão para pensar que a crença é verdadeira, ou então explicar como tal aceitação possa estar epistemicamente justificada sem ser racional. É porque eu não posso ver uma forma plausível de fazer quaisquer dessas coisas que o externalismo me parece, a despeito da indubitável engenhosidade de seus defensores, ser essencialmente uma evasão antes do que uma solução dos problemas epistemológicos clássicos. ${ }^{23}$

$22 \mathrm{Na}$ caracterização da distinção entre "informação" e "conhecimento" Lehrer exibe o que é - desde minha perspectiva, de todo modo - uma de suas principais qualidades como epistemólogo: a clareza argumentativa, a indisposição a rodeios conciliatórios e acrobacias retóricas de qualquer tipo. Assim, ao invés de caracterizar o objeto de estudo do externalismo como "um certo tipo de conhecimento" distinto de "outro tipo de conhecimento" que seria o objeto de estudo do internalismo, ele prefere marcar a diferença de maneira mais clara ao identificar na posse de informações o tema mais próprio da epistemologia externalista: "todas as teorias externalistas compartilham um defeito comum, a saber, que elas proporcionam descrições da posse da informação, a qual pode ser opaca ao sujeito, ao invés daquelas da obtenção de conhecimento transparente" (LEHRER, 2000, p. 185).

Não obstante uma tal posição mais dura ser às vezes caracterizada como uma recusa demasiado tendenciosa de uma certa caracterização do conhecimento - é o que, por exemplo, Fred Dretske denuncia em Two Conceptions of Knowledge: Rational vs. Reliable Belief (DRETSKE, 2000, pp. 80-93) - essa recusa não é feita nem de forma precipitada, nem de forma dogmática.

23 BONJOUR, 1989, p. 279. 
E, no entanto, a plausibilidade de certos aspectos da análise externalista da justificação epistêmica não pode ser explicada simplesmente desde a "engenhosidade de seus defensores". Claramente, há muito mais em jogo aqui. Embora o externalismo em sua versão mais prosaica seja uma descrição equivocada do que está envolvido no processo e de como se articula a estrutura do conhecimento, isso não impede que encontremos ali ingredientes fundamentais para uma descrição correta de um e outra. Cabe aos defensores do externalismo a tarefa de destacar e desenvolver tais ingredientes.

\section{Um breve balanço, à guisa de conclusão}

O fundacionismo é uma teoria (ou melhor, um conjunto de teorias) que tem precedência - precedência histórica, ao menos - sobre as demais respostas oferecidas ao problema do regresso, mas que se revela prenhe de problemas insatisfatoriamente resolvidos. Dois de tais problemas foram alvos de atenção aqui. $\mathrm{O}$ primeiro diz respeito à inadequabilidade de uma associação entre as noções de "crença básica" e de "justificação". Se tive sucesso em fazer o leitor me acompanhar ao longo do breve percurso argumentativo que atrás percorri, terei denunciado a problematicidade da idéia de crença básica justificada. Nesse caso, o apelo intuitivo da noção de "base epistêmica" e a às vezes sugerida incontestável prioridade teórica do fundacionismo sobre as respostas alternativas ao problema do regresso terão sido colocados em xeque. A noção de crença justificada terá, nesse caso, se apresentado como incompatível com a de basicidade, pois esta não se coaduna com a assertividade inerente àquela. O segundo problema diz respeito à caracterização das supostas crenças básicas do ponto de vista de sua falibilidade ou infalibidade. Numa ou noutra circunstância, as crenças básicas terão tido sua basicidade denunciada em função da necessidade de que elas sejam avaliadas e sustentadas desde o sistema doxástico como um todo.

Quanto à vertente externalista do fundacionismo, esta parece maculada pela carência da reivindicação de que, não apenas um sujeito epistêmico se encontre em circunstâncias objetivamente favoráveis para a formação de crenças verdadeiras mas, fundamental e indispensavelmente, reconheça tais circunstâncias enquanto dotadas de tais características. Sem esse reconhecimento, a caracterização epistemológica se revela empobrecida e incapaz de dar conta do problema do regresso epistêmico. Informação não é conhecimento, pois o conhecimento exige que a justeza da informação seja identificada. Na formulação primária em que o analisei aqui, portanto, 
tampouco o fundacionismo externalista parece capaz de dar uma resposta satisfatória ao problema da justificação epistêmica.

Se tais avaliações estão corretas, a posição fundacionista está comprometida por um conjunto de problemas que, se não são insolúveis, são pelo menos suficientemente sérios para motivar a busca de uma solução alternativa para o problema do regresso epistêmico. É num tal cenário que a posição coerentista surge como uma opção epistemologicamente relevante. A análise do coerentismo e dos problemas que lhe são próprios, porém, é uma tarefa para cumprir em outra oportunidade..$^{24}$

\section{Referências Bibliográficas}

AUDI, Robert (Ed.). The Cambridge Dictionary of Philosophy. 2. ed. Cambridge: Cambridge University Press, 1999.

BONJOUR, Laurence. Can Empirical Knowledge Have a Foundation? American Philosophical Quarterly, 15, p. 1-13, 1978. (As páginas referidas são de Moser (1986).

BONJOUR, Laurence. The Structure of Empirical Knowledge. Cambridge, Mass.: Harvard University Press, 1985.

BONJOUR, Laurence. Replies and Clarifications. In: BENDER, John (Ed.). The Current State of the Coherence Theory, 1989. p. 276-292.

BONJOUR, Laurence. The Dialetic of Foundationalism and Coherentism. In: GRECO, John, SOSA, Ernest (Ed.). The Blackwell Guide to Epistemology. Oxford: Blackwell, 1999.

BONJOUR, Laurence; SOSA, Ernest. Epistemic Justification: Internalism vs. Externalism, Foundations vs. Virtues. Oxford: Blackwell Publishing, 2003.

BURDZINSKI, Júlio César. Justificação, Coerência e Circularidade. Veritas, Perspectives in Contemporary Epistemology, Porto Alegre, v. 50, n. 4, 2006.

DANCY, Jonathan; SOSA, Ernest (Ed.). A Companion to Epistemology. Oxford: Blackwell, 1992.

DRETSKE, Fred. Perception, Knowledge, and Belief. Cambridge: Cambridge University Press, 2000.

FLORES, Tito A. Racionalidade Epistêmica e o Processo de Justificação. 2004. Tese (Doutorado em Filosofia) - Faculdade de Filosofia e Ciências Humanas, Pontifícia Universidade Católica do Rio Grande do Sul, Porto Alegre, 2004.

GOLDMAN, Alvin I. What is Justified Belief. In: PAPPAS, G. S. (Ed.). Justification and Knowledge. Dordrecht: D. Reidel, 1979. (Reimpresso em MOSER, 1986).

24 Em "Justificação, Coerência e Circularidade" (BURDZINSKI, 2006) esboço minha versão do coerentismo e tento responder àquela que creio ser a acusação mais fundamental de que ele pode ser alvo: a acusação de cometer circularidade. 
KLEIN, Peter. Human Knowledge and the Infinite Regress of Reasons. Philosophical Perspectives, Oxford, Blackwell, n. 13, p. 297-325, 1999.

LEHRER, Keith. Theory of Knowledge. 2. ed. Boulder; Colorado: Westview Press, 2000.

MOSER, Paul K. (Ed.). Empirical Knowledge: Readings in Contemporary Epistemology. Cambridge: Cambridge University Press, 1986. 